\title{
PSICOBIOLOGIA DO ANABOLISMO: UM ESTUDO BIBLIOGRÁFICO DAS ALTERAÇÕES NO SISTEMA DE RECOMPENSA CEREBRAL DECORRENTES DO CONSUMO INDISCRIMINADO DE ESTEROIDES ANABOLIZANTES \\ PSYCHOBIOLOGY OF ANABOLISM: A BIBLIOGRAPHIC STUDY OF CHANGES \\ IN THE BRAIN'S REWARD SYSTEM RESULTING FROM INDISCRIMINATE CONSUMPTION OF ANABOLIC STEROIDS
}

\author{
Eduardo Mendes Medeiros ${ }^{1}$, Danielle Fernandes Vasconcelos Alves², Carlos Renato Alves Nogueira ${ }^{3}$ \\ PSIQUE・e-ISSN 2183-4806 • VOLUME XIV •ISSUE FASCÍCULO 2 \\ $1^{\text {ST }}$ JULY JULHO - 31 $1^{\text {TH }}$ DECEMBER DEZEMBRO 2018 •PP. 30-58 \\ DOI: https://doi.org/... \\ Submited on August $6^{\text {th }}, 2017 \mid$ Accepted on May 18 th, 2018 ( 2 rounds of revision) \\ Submetido a 6 de agosto, 2017 | Aceite a 18 de maio, 2018 (2 rondas de revisão)
}

\begin{abstract}
Resumo
A presente pesquisa investigou se o consumo de esteroides anabolizantes androgênicos pode causar alteração no sistema de recompensa cerebral. Trata-se de uma pesquisa qualitativa, na qual foi utilizado o método bibliográfico do estado da questão, realizando uma análise da situação atual em que se encontra esse objeto de pesquisa no meio científico internacional. Consultouse a plataforma de periódicos CAPES e, inicialmente, realizou-se uma busca por pesquisas publicadas em língua portuguesa utilizando os descritores: "Sistema de recompensa cerebral", "Esteroides anabolizantes androgênicos" e a combinação deles. Posteriormente, ao constatar-se a escassez de literatura científica brasileira sobre este assunto, realizou-se uma busca de artigos publicados em língua estrangeira. Efetuou-se um levantamento de artigos, livros e trabalhos acadêmicos que abordam questões pertinentes que ajudaram a responder aos objetivos deste estudo. Assim, foi definido o que são os esteroides anabolizantes androgênicos. Analisou-se a estreita relação entre o uso de substâncias psicoativas e o mecanismo de recompensa e prazer do cérebro. Realizou-se uma análise global no qual foi compreendido que o consumo recorrente de esteroides anabolizantes pode alterar o funcionamento do sistema de recompensa cerebral que, por sua vez, pode resultar na toxicodependência e em outros prejuízos psicobiológicos que afetam a qualidade de vida de seus usuários.
\end{abstract}

Palavras-chave: esteroides anabolizantes, sistema de recompensa cerebral, psicobiologia.

\footnotetext{
${ }^{1}$ Faculdade Maurício de Nassau, Fortaleza, Brasil, E-mail: eduardopsicologia88@gmail.com. ORCID: https://orcid.org/0000-0003- 0453-7430

2 Faculdade Maurício de Nassau, Fortaleza, Brasil, E-mail: d_alves2@hotmail.com. ORCID: https://orcid.org/0000-0002- 2102-7670

3 Faculdade Maurício de Nassau, Fortaleza, Brasil, E-mail: carlosrenato.ce@bol.com.br; renato_farmaco@hotmail.com. ORCID: https://orcid.org/0000-0001- 9264-605X
} 


\begin{abstract}
This research investigated whether the consumption of androgenic anabolic steroids can cause alteration in the brain's reward system. It is a qualitative research in which the bibliographical method of the state of the question was used; an analysis was made about the current situation of the research object in the international scientific field. The CAPES journal platform was consulted, and initially, a search was made to find research published in the Portuguese language using the descriptors: "Brain reward system", "Anabolic-androgenic steroids" and the combination of both. Then, after realizing that the Brazilian scientific literature about this subject was scarce, a search was made to find articles published in other languages. A survey of articles, books, and scholarly works addressing pertinent questions was carried out and they helped to answer the objectives of this study. Thus, the definition of what androgenic anabolic steroids are was advanced. The close relationship between the use of psychoactive substances and the brain's mechanism of reward and pleasure was analyzed. A global analysis was made, which indicated that the recurrent consumption of anabolic steroids can alter the functioning of the brain' s reward system, which can also result in chemical addiction and other psychobiological damages that affect the quality of life of users.
\end{abstract}

Keywords: anabolic steroids, brain's reward system, psychobiology.

Esteroides Anabolizantes Androgênios (EAA) são fármacos produzidos a partir de uma derivação sintética da testosterona que é o hormônio ${ }^{1}$ sexual masculino. Seu uso farmacoterapêutico é prescrito para tratar casos clínicos específicos, como: atrofia muscular severa; má formação dos testículos; reposição hormonal em casos de hipogonadismo²; na contracepção hormonal masculina, como também em casos de outras patologias (Boff, 2010; Lemos et al., 2012; Lopes, 2015; Nogueira, 2015; Silva, Danielski, \& Czepielewski, 2002).

No entanto, estas drogas são utilizadas de forma indiscriminada para fins estéticos por indivíduos que não são atletas, visto que estes percebem estas substâncias como "a fórmula" da beleza masculina. Estes hormônios possuem efeitos atrativos tanto anabólicos, visto que promovem a hipertrofia muscular, quanto androgênicos, pois promovem o aumento das características secundárias masculinas (Martins et al., 2005; Olivardia, 2001; Pereira, 2009; Pope, Phillips, \& Olivardia, 2000; Silva et al., 2002; Venâncio, Nóbrega, Tufik, \& Mello, 2010). Grande parte deste público é composto por pessoas jovens do gênero masculino que praticam halterofilismo amador, no intuito de melhorar a aparência, e fazem uso destas substâncias indiscriminadamente, podendo tal prática tornar-se um problema contemporâneo de saúde

\footnotetext{
${ }^{1}$ Hormona, em português europeu, designa as várias substâncias produzidas por glândulas endócrinas (tiróide, ovários, testículos, hipófise, suprarrenais, etc.) que, ao passarem para os vasos sanguíneos, têm um efeito específico sobre as atividades de outros órgãos do corpo humano (Bear, Connors, \& Paradiso, 2002).

${ }^{2} \mathrm{O}$ déficit de testosterona ou hipogonadismo é uma síndrome clínica que afeta a vida sexual, os ossos, o nível de energia, a força dos músculos e até o humor de indivíduos do gênero masculino. Este déficit é uma diminuição da testosterona, que é o principal hormônio masculino (Lopes, 2015).
} 
pública (Abrahin, Moreira, Nascimento, \& Sousa, 2011; Dartora, Wartchow, \& Acelas, 2014; Sagoe, Molde, Andreassen, Torsheim, \& Pallesen, 2014; Olivardia, 2001; Pedroso, 2012; Pereira, 2009; Pope et al., 2000).

Arnedo, Martínez-Sanchís, e Salvador (1999), Sauerbier (2014) e Tavares (2015) advertem-nos que quando os Esteroides Anabolizantes Androgênios (EAA) são utilizados de forma indiscriminada, tornando-se drogas de abuso, podem ocasionar danos significativos para a qualidade de vida dos seus usuários, pois trazem prejuízos psicobiológicos, reversíveis e irreversíveis, sociais e ocupacionais (McGaugh, Weinberger, \& Whalen, 1970; Mello, Boscolo, Esteves \& Tufik, 2005; Sauerbier, 2014). Para além destes prejuízos, existe uma diversidade de riscos para a saúde de uma quantidade crescente de pessoas que consomem esteroides anabolizantes de forma indiscriminada, pois as pessoas não estão conscientes dos efeitos nocivos que estes fármacos podem causar, pelo fato de modificarem o funcionamento do sistema de recompensa cerebral (Abrahin \& Sousa, 2013; Arnedo et al., 1999; Ferreira, 2007; Lemos et al., 2012; Kaufman et al., 2015; Ranjan, Parmar, Pattanayak, \& Dhawan, 2014; Sauerbier, 2014; Tavares, 2015).

Sistema de recompensa cerebral é um termo utilizado pela Psicobiologia, uma área da ciência psicológica que procura investigar os fenômenos ocorridos no sistema nervoso central, que estão por trás dos comportamentos e processos mentais (Atkinson, Atkinson, Smith, Bem, \& Nolen-Hoeksena, 2002; Bueno, 2016; Dewsbury, 1991; McGaugh et al., 1970; Silva, 1981). Este sistema é composto por um circuito de zonas cerebrais que são interligadas e estão envolvidas nas atividades de produção do prazer, emoção e motivação, pois qualquer estímulo excitatório nesta zona neural é interpretado pelo cérebro como uma recompensa (Atkinson et al., 2002; Batista, Almeida, Fadel, \& Bressan, 2010; Costa, 2015; HerculanoHouzel, 2012; Olds, 1970; Olds \& Milner, 1954; Rossa, 2012; Rossa \& Rossa, 2011; Teixeira, 1998; Thompson, 1999).

É, neste contexto, que o presente estudo se situa. O seu objetivo foi o de investigar se o consumo de esteroides anabolizantes androgênicos pode causar alteração no sistema de recompensa cerebral. Para responder à pergunta de investigação, efetuamos um levantamento de artigos e trabalhos acadêmicos que abordam questões pertinentes através de uma análise do estado da questão. Este método consiste em uma técnica de pesquisa que tem por finalidade situar, delimitar, clarificar e caracterizar como se encontra o objeto de investigação no estado atual da ciência, através de uma consulta seletiva e crítica das produções cientificas, restringindo-se aos estudos e parâmetros próximos às especificidades do interesse do pesquisador (Nobrega-Therrien \& Therrien, 2010; Vosgerau \& Romanowski, 2014). Assim, a realização deste estudo se justifica por abordar um tema atual, à medida que promove a reflexão sobre as alterações que estas substâncias podem causar ao cérebro e na qualidade de vida dos seus consumidores. Contribui com o estudo do tema ao nível da psicobiologia evidenciando que alterações no cérebro e nos neurônios tomam parte neste processo. Deste modo, esta investigação contribui para a discussão deste problema de saúde pública. 


\section{Método}

Para cumprir com os objetivos desta pesquisa, realizou-se um estudo indireto, bibliográfico, com abordagem qualitativa, que se justifica, pois, a análise qualitativa se trata de um constructo científico que busca a compreensão de fenômenos complexos não mensurados, vivenciados por pessoas, abrindo, desta forma, perspectivas para estudos posteriores, concretizando a construção intersubjetiva do conhecimento (Minayo, 2012). Posto que a pesquisa qualitativa é relevante na consolidação do conhecimento da ciência psicológica, pois ela possibilita ao pesquisador atuar na prática da atividade científica, decompondo a singularidade do fenômeno investigado, gerando dados que sustentam as evidências acerca de seus objetivos (Campos, 2008). Elegeu-se como método de investigação, o estado da questão, em virtude do seu caráter analítico e crítico, e de sua função de situar, delimitar, clarificar e caracterizar como se encontra o objeto de investigação no estado atual da ciência, através de uma consulta seletiva e crítica das produções cientificas, restringindo-se aos estudos e parâmetros próximos às especificidades do interesse do pesquisador. O estado da questão se distingue do estado da arte, pois este outro método tem como objetivo mapear e discutir a produção científica/acadêmica em determinado campo do conhecimento (Nobrega-Therrien \& Therrien, 2004, 2010; Vosgerau \& Romanowski, 2014).

\section{Percurso Metodológico}

Consultamos a Plataforma Científica de Periódicos da Coordenação de Aperfeiçoamento de Pessoal de Nivel Superior (CAPES). Fizemos uma pesquisa do que foi publicado sobre este assunto nos últimos 30 anos. Posteriormente, delimitou-se a pesquisa para os últimos 10 anos, utilizando os descritores e suas combinações: "Sistema de recompensa cerebral" e "Esteroides anabolizantes androgênicos". A referida coleta de dados ${ }^{3}$ foi realizada no período de agosto de 2016 a fevereiro de 2018.

Inicialmente, realizamos esta investigação pesquisando apenas publicações científicas em língua portuguesa. Posteriormente, em busca de publicações científicas em língua estrangeira, consultamos as bases de dados eletrônicas: American Psychological Association (APA), Ebsco, Emerald, Sagepub, Springer, PubMed e Elsevier, onde utilizamos os mesmos descritores e suas combinações em língua inglesa.

\section{Critérios de Inclusão}

Sistema de recompensa cerebral: livros; ensaios; artigos originais e de revisão bibliográfica sobre o sistema de recompensa cerebral. Estudos que fazem uma análise conceptual da ação psicobiológica deste sistema cerebral e o papel deste sistema na toxicodependência. Estudos que se aproximam do interesse do pesquisador, o de compreender a relação entre o consumo de esteroides anabolizantes, as alterações que ocorrem neste sistema neural e que afetam o comportamento e a qualidade de vida dos indivíduos que consomem estes fármacos de forma indiscriminada.

\footnotetext{
${ }^{3}$ Equivalente ao termo recolha de dados, mais utilizado no português europeu.
} 
Esteroides anabolizantes: estudos que realizam uma análise conceptual dos esteroides anabolizantes; estudos que relacionam o consumo de esteroides anabolizantes e a ação destas substâncias no sistema de recompensa do cérebro, no sistema nervoso central; estudos de caso com seres humanos; ensaios clínicos; estudos experimentais com modelos animais. Anais de eventos acadêmicos, revisões bibliográficas e estudos que se aproximam do objetivo do estudo, a fim de saber a situação em que se encontra, atualmente, esta questão da pesquisa no meio científico.

\section{Critérios de Exclusão}

Foram excluídos os estudos que não levam em consideração a ação dos esteroides anabolizantes andrógenos sobre o sistema de recompensa do cérebro; os estudos que contenham pouca análise conceptual dos objetos de estudo; os estudos que se distanciam da questão abordada e artigos publicados que se repetem.

\section{Procedimentos}

Inicialmente, definimos a pergunta que norteou a realização deste estudo: $O$ consumo de esteroides anabolizantes androgênicos pode causar alterações no sistema de recompensa cerebral? Ao realizarmos a pesquisa na plataforma CAPES, combinando os descritores "Sistema de recompensa cerebral e Esteroides anabolizantes", foram encontradas apenas 6 pesquisas publicadas no Brasil, em língua portuguesa, que por atenderem aos critérios de inclusão, foram integralmente lidas e analisadas. Ao realizarmos uma busca de trabalhos científicos publicados em língua estrangeira, nas bases de dados supracitadas, atendendo aos critérios inclusão, foram selecionados 55 artigos, que abrangem o período temporal 1988-2018, para mapearmos (analisarmos) a evolução das pesquisas e o seu estado atual. Os artigos selecionados atenderam a todos os critérios de inclusão. Posteriormente, foram integralmente lidos e analisados (Gráfico 2). Para auxiliar na análise dos dados, elaborou-se uma tabela, categorizando os materiais selecionados, organizando-os das publicações mais antigas para as mais recentes, identificando o nome dos autores e a metodologia utilizada nas obras analisadas (Tabela 2).

\section{Resultados e Discussão}

\section{Mecanismo de Adição do Sistema de Recompensa Cerebral e os Esteroides Anabolizantes}

O sistema de recompensa cerebral é composto por um circuito de zonas cerebrais que são interligadas e estão envolvidas nas atividades de produção do prazer, emoção e motivação, pois qualquer estímulo excitatório nesta zona neural é interpretado pelo cérebro como uma recompensa (Atkinson et al., 2002; Batista et al., 2010; Ferreira, 2007; Herculano-Houzel, 2012; Olds, 1970; Teixeira, 1998). É caracterizado por seus componentes centrais: o núcleo accumbens, área tegmentar ventral e córtex pré-frontal e seu envolvimento com o sistema límbico (associado às emoções), com os principais centros responsáveis pela memória (amígdala e hipocampo), feixe prosencefálico medial, córtex orbitofrontal e córtex cingulado (Atkinson et al., 2002; Costa, 2015; Herculano-Houzel, 2012; Rossa \& Rossa, 2011; Rossa, 2012). 
As drogas atuam no sistema de recompensa cerebral mimetizando os neurotransmissores e estimulando o conjunto de neurônios que compõem o sistema de recompensa cerebral (Castro, 2004; Costa, 2015; Ferreira, 2007; Standaert \& Galanter, 2012). Quimicamente, os neurotransmissores são moléculas relativamente pequenas, produzidas pelos neurônios, que são células nervosas que compõem o cérebro. Os neurônios se comunicam através destes mensageiros, que agem como mediadores liberados por grupos específicos de neurônios nas sinapses. As sinapses são microrregiões localizadas entre um neurônio e outro que, ao terem acesso aos seus receptores nos neurônios pós-sinápticos, determinam sensações, percepções sensoriais e mudanças de comportamento (Atkinson et al., 2002; Costa, 2015; Ferreira, 2007; Lent, 2004; Nogueira, 2015).

Os neurônios responsáveis pela ativação do sistema de recompensa cerebral estão localizados no tronco cerebral superior e estendem os seus axônios até o prosencéfalo. Estes neurônios usam o neurotransmissor dopamina para transmitirem a sua mensagem. Estes mesmos neurônios também são ativados por muitos tipos de drogas, algumas destas são notoriamente poderosas em sua capacidade de produzir adição. São dotadas da capacidade de produzir mudanças permanentes neste sistema neural, causando no usuário um desejo de voltar a consumi-las, mesmo depois de ter passado a abstinência (Atkinson et al., 2002; Batista et al., 2010; Bear et al., 2002; Castro, 2004; Costa, 2015; Ferreira, 2007; Herculano-Houzel, 2005; Olds, 1970; Standaert \& Galanter, 2012; Teixeira, 1998).

No percurso desta investigação, constatou-se que grande parte dos autores revisados acentuam a função do neurotransmissor dopamina na ativação do sistema de recompensa cerebral, pelo fato de a dopamina ter uma poderosa propriedade indutora de reforço positivo neste sistema, pois este neurotransmissor é ativado durante o consumo de substâncias psicoativas. Os mesmos autores também salientam que a diminuição da serotonina, neste sistema neural, influencia a liberação dopaminérgica. Ambos os neurotransmissores estão diretamente ligados à toxicodependência e à abstinência (Arnedo et al., 1999; Atkinson et al., 2002; Batista et al., 2010; Bear et al., 2002; Castro, 2004; Costa, 2015; Clark, Lindenfeld, \& Gibbons, 1996; Ferreira, 2007; Graeff, 1995; Grönbladh, Nylander, \& Hallberg, 2016; Herculano-Houzel, 2012; Kindlundh, Lindblom, Bergström, Wikberg, \& Nyberg, 2001; Lent, 2004; Linden \& Manns, 1980; Olds, 1970; Olivardia, 2001; Pope et al., 2000; Rossa \& Rossa, 2011; Rossa, 2012; Standaert \& Galanter, 2012; Teixeira, 1998). Os neurotransmissores supracitados também estão ligados ao fenômeno da fissura (ou craving), que se caracteriza como um desejo compulsivo de consumir determinada droga, e induz à neuroadaptação cerebral que altera a memória dos estímulos de consumir drogas (Araújo, Oliveira, Pedroso, Miguel, \& Castro, 2008). Por isso, consideramos este como um ponto de consistência entre as diferentes abordagens revisadas.

Os neurônios do sistema de recompensa cerebral, pertencentes à área ventral tegmental, lançam dopamina para o núcleo accumbens, para o córtex pré-frontal, para a amígdala e para o hipocampo. Por isso, as alterações na transmissão dopaminérgica desempenham um papel crucial na modulação do fluxo de informação no circuito límbico, comprometendo as interligações desta via, visto que embora as drogas sejam quimicamente diferentes e mesmo elas não tendo os mesmos alvos moleculares, todas as drogas têm em comum a promoção do aumento da concentração de dopamina neste sistema neural (Castro, 2004; Costa, 2015; Graeff, 1995; Standaert \& Galanter, 2012). Desta forma, as drogas levam o usuário a experimentar, desde 
o prazer da excitação neural, causador de poderosas neurorrecompensas, à toxicodependência desta mesma recompensa por desencadearem a liberação de dopamina no núcleo accumbens deste sistema (Castro, 2004; Costa, 2015). Este núcleo registra nossas sensações positivas e orquestra o sistema de recompensa do cérebro, fazendo com que este não meça esforços para obter aquilo que lhe causa prazer. A droga que causa tal prazer altera o limiar de equilíbrio do sistema de recompensa cerebral, levando o cérebro a desenvolver tolerância a esta droga e a buscar compulsivamente uma dose maior, pois este sistema se habituou ao prazer que esta droga lhe propiciou (Castro, 2004; Costa, 2015; Herculano-Houzel, 2012).

Com o processo de estimulação acima descrito, o núcleo accumbens libera outro neurotransmissor, chamado ácido gama-aminobutírico (GABA), na área ventrotegmental, que age como inibidor, trazendo a sensação de tranquilidade e alívio da ansiedade, pois tem a finalidade de moderar a atividade dopaminérgica (Garcia, 2013). A dopamina, por sua vez, tem a capacidade de modificar a atividade elétrica dos neurônios que a recebem, neste caso, os do núcleo accumbens (Castro, 2004; Costa, 2015; Herculano-Houzel, 2005; Standaert $\delta$ Galanter, 2012). Por isso, o grau de ativação do sistema de recompensa pode ser inferido, tanto pelo grau de atividade do núcleo accumbens, quanto pela quantidade de dopamina liberada sobre ele durante qualquer atividade potencialmente prazerosa. Portanto, mais dopamina significa maior ativação do núcleo accumbens (Herculano-Houzel, 2005). As drogas de abuso, em sua maioria, aumentam a concentração de dopamina na via de recompensa, estimulando, indiretamente, os neurônios produtores de dopamina na área tegmental ventral para que eles gerem mais potencial de ação. Algumas drogas bloqueiam a recaptação de dopamina, causando uma maior concentração desta na via de recompensa (Araújo et al., 2008; Atkinson et al., 2002; Bear et al., 2002; Castro, 2004; Costa, 2015; Graeff, 1995; Herculano-Houzel, 2012; Lent, 2004; Standaert \& Galanter, 2012).

Esses autores afirmam que, desta forma, a dopamina se acumula na fenda sináptica em uma quantidade muito maior do que normalmente ocorre, provocando uma estimulação contínua. Esta super estimulação dos neurônios pós-sinápticos é responsável pela euforia prolongada e intensa, experimentada por usuários de drogas. Exposições repetidas a altas quantidades de dopamina causada pelas drogas, eventualmente, dessensibilizam o sistema de recompensa. Ele deixa de responder aos estímulos cotidianos, de tal forma que a única coisa que se torna gratificante é a droga. Assim, as drogas alteram as prioridades da vida da pessoa. Depois de um tempo, até mesmo a droga perde a sua capacidade de recompensa e as doses necessárias para se atingir o efeito de recompensa tornam-se, cada vez mais elevadas, podendo levar a uma overdose.

De um modo semelhante, o sistema de recompensa cerebral é fundamental no reforço da toxicodependência de esteroides anabolizantes androgênicos (Gráfico 1; Arnedo et al., 1999; Arnedo et al., 2000; Clark et al.,1996; Grönbladh et al., 2016; Kanayama, Brower, Wood, Hudson, \& Pope, 2009a; Kaufman et al., 2015; Kindlundh et al., 2001; Lemos et al., 2012; Milhorn, 2018; Pedroso, 2012; Ranjan et al., 2014; Ribeiro, 2014; Sauerbier, 2014; Seitz et al., 2017; Tavares, 2015; Wood, 2008). Os estudos revelam que as variações dos níveis de andrógenos sintéticos afetam os níveis de dopamina nesta área do cérebro, pois as concentrações de testosterona no núcleo accumbens, que têm muitos receptores de andrógenos, causadores da interação entre a testosterona e o sistema de recompensa cerebral, tal interação, produz intensas sensações de prazer ocasionando uma hiperestimulação, fazendo com que os seus usuários passem a buscar obter doses maiores destas substâncias (Arnedo et al., 1999; Ribeiro, 2014; Wood, 2008). 
O consumo crônico dos esteroides anabolizantes androgênicos pode causar a diminuição prolongada da neurotransmissão serotoninérgica (do neurotransmissor serotonina), como também, afeta alguns neuroreceptores na área do sistema límbico (Tabela 1).

Tabela 1

Alterações Neurais decorrentes do Consumo de Esteroides Anabolizantes

\begin{tabular}{|c|c|c|}
\hline \multicolumn{3}{|c|}{ Consumo indiscriminado de Esteroides Anabolizantes Androgênicos } \\
\hline \multicolumn{3}{|c|}{ Alterações psicobiológicas } \\
\hline \multicolumn{3}{|c|}{ Modifica o funcionamento do Sistema de Recompensa Cerebral humano } \\
\hline Neuroadaptação & Toxicodependência & $\begin{array}{c}\text { Abstinência - casos extremos } \\
\text { Fissura }\end{array}$ \\
\hline $\begin{array}{l}\text { Altera os níveis metabolitos } \\
\text { de monoaminas }\end{array}$ & Altera os níveis de neuroformonas & Altera os níveis de neuropeptídeos \\
\hline $\begin{array}{l}\text { Aumento dos níveis da } \\
\text { substância P }\end{array}$ & $\begin{array}{l}\text { Aumento dos níveis do ácido } \\
\text { 5-hidroxiindolacético }\end{array}$ & $\begin{array}{c}\text { Diminuição dos níveis } \\
\text { de 3-metoxi-4-hidroxifenilglicol }\end{array}$ \\
\hline $\begin{array}{l}\text { Reduz a depuração } \\
\text { da norepinefrina }\end{array}$ & Aumento dos níveis da vasopressina & Aumento dos níveis de glutamato \\
\hline Neurointoxicação & Diminuição e morte dos neurônios & Reduz a conectividade funcional \\
\hline Altera a neuroplasticidade & Atrofia a substância cinzenta & Diminuição da substância branca \\
\hline Neurodegeneração & Concursão & Encefalopatia traumática crônica \\
\hline Perda das atividades cerebrais & Acidente Vascular cerebral precoce & $\begin{array}{l}\text { Morte cerebrovascular subta/ } \\
\text { precoce }\end{array}$ \\
\hline $\begin{array}{l}\text { Altera o sistema } \\
\text { monoaminérgico }\end{array}$ & Diminuição prolongada da serotonina & Elevação da dopamina \\
\hline Afeta o Sistema Límbico & Comportamentos agressivos & Surtos de agressividade \\
\hline Agitação & Fadiga & Anorexia \\
\hline $\begin{array}{l}\text { Prejuizos no sistema } \\
\text { neuro-hormonal }\end{array}$ & Depressão & Disturbios de humor \\
\hline Distúrbios do sono & Sindrome de apneia & Prejuizos da memória visuoespacial \\
\hline Distúrbios psíquicos & Ansiedade & Baixa autoestima \\
\hline Mania & Hipomania & Mania de grandesa \\
\hline Medo & Alterações emocionais & $\begin{array}{l}\text { Alteração nos processos mentais } \\
\text { de motivação e recompensa }\end{array}$ \\
\hline Prejuízo do julgamento & Obsessão & Psicose \\
\hline Ilusões psicóticas & Ideação suicída & Alucinações \\
\hline Delírio & Alterações na personalidade & Alteração do comportamento sexual \\
\hline Baixa dos níveis de testosterona & Hipogonadismo adquirido & Redução da libido \\
\hline Perda das atividades cognitivas & Distorção da autoimagem corporal & Dismorfia corporal \\
\hline
\end{tabular}


Os casos de toxicodependência de esteroides anabolizantes androgênicos têm semelhanças com a toxicodependência de outras substâncias psicoativas clássicas (Gráfico 1; Arnedo et al., 1999; Kanayama, Hudson, \& Pope, 2009; Kashkin, \& Kleber, 1989; Midgley, Heather, \& Davies, 1999; Tennant, Black, \& Voy, 1988).

Posto que, na toxicodependência a estes fármacos, as monoaminas, como a serotonina e a dopamina, estão implicadas na mediação do efeito dos esteroides anabolizantes no sistema de recompensa do cérebro (Arnedo et al., 1999; Clark et al., 1996; Grönbladh et al., 2016; Kanayama, Brower, Wood, Hudson, \& Pope, 2009a; Kindlundh et al., 2001; Lemos et al., 2012; Midgley et al., 1999; Pedroso, 2012; Ranjan et al., 2014; Ribeiro, 2014; Sauerbier, 2014; Seitz et al., 2017; Westlye, Kaufmann, Alnæs, Hullstein, \& Bjørnebekk, 2017). Em destaque, a dopamina, que tem a capacidade de mediar os efeitos de recompensa destas substâncias (Arnedo et al., 1999; Clark et al., 1996; Olivardia, 2001). Este modelo de adição aos esteroides anabolizantes em seres humanos indica que eles compartilham um mecanismo molecular comum de toxicodependência dos opióides (Arvary \& Pope, 2000; Kanayama, Hudson, \& Pope, 2009; Kashkin \& Kleber, 1989; McBride, Williamson, \& Petersen, 1996; Mhillaj et al., 2015; Wood, 2008; Wines, Gruber, Pope, \& Lukas, 1999). Segundo este modelo, os usuários de esteroides anabolizantes apresentam grande risco de desenvolver toxicodependência de opióides (McBride et al., 1996; Mhillaj et al., 2015; Wood, 2008; Wines et al., 1999).

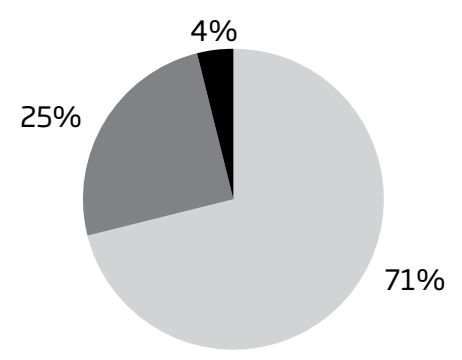

Trabalhos que apontam que o modelo de toxicodependência dos EAA se assemelha ao modelo de adição de drogas clássicas

Trabalhos que apontam ambiguidade no modelo de adição dos EAA

Trabalhos em que os resultados foram contraditórios

Gráfico 1. Proporção dos dados encontrados nas publicações analisadas.

Kanayama et al. (2009a) esclarecem a diferença entre o abuso de drogas clássicas e o abuso de esteroides anabolizantes. Os usuários não ingerem os anabolizantes para alcançar um efeito imediato de euforia/prazer, que pode causar uma intoxicação aguda imediata, pois, diferente das drogas clássicas. As pessoas consomem os anabolizantes durante um período pré-planejado de ciclos, que duram muitas semanas, para obter uma recompensa posterior de hipertrofia muscular, que age no indivíduo como um incentivo psicológico para continuar a consumir os esteroides anabolizantes (Atkinson et al., 2002). 
A evolução das pesquisas empíricas demonstra que tanto os efeitos mioativos, quanto os efeitos psicoativos, dos esteroides anabolizantes contribuem para o desenvolvimento da toxicodependência (Brower, 2002; Lemos et al., 2012). Porém, a literatura ainda sugere que, em seres humanos, é difícil separar os efeitos psicoativos, que levam aos usuários a desenvolverem toxicodependência aos esteroides anabolizantes, dos efeitos de incentivo e recompensa do seu uso, devido aos seus efeitos anabolizantes que causam a sedutora hipertrofia muscular (Wood, 2008).

Os resultados do estudo de Negus, Pope, Kanayama, Wines, e Fischer (2001) levantaram questionamentos sobre este modelo de adição supracitado, pois, no mesmo, não foi encontrado o fenômeno da abstinência após o consumo de altas doses de esteroides anabolizantes (Gráfico 1). Isso favoreceu o questionamento de que estas substâncias causam toxicodependência (Arnedo et al., 1999; Lemos et al., 2012; Negus et al., 2001; Pedroso, 2012; Sauerbier, 2014). Todavia, o estudo de Negus et al. (2001) foi realizado em macacos rhesus. Por isso, salientamos a necessidade de realização de novas pesquisas em seres humanos para esclarecer completamente se o mesmo mecanismo de toxicodependência é compartilhado entre drogas clássicas, opióides e esteroides anabolizantes. Ainda, discutindo as hipóteses sobre o modelo de adição dos esteroides anabolizantes, nesta análise, observou-se que Mhillaj et al. (2015) inferem que os esteroides anabolizantes androgênicos agem por meio de um mecanismo de reforço mais brando se comparado à heroína e à cocaína (Gráfico 1). No entanto, este modelo parece ser análogo ao mecanismo de reforço, descrito para a cafeína, nicotina e benzodiazepínicos (Mhillaj et al., 2015).

Brower (2002) também apresenta um modelo para explicar a toxicodependência aos esteroides anabolizantes com dois estágios. No primeiro estágio, a ação decorrente do consumo dos esteroides anabolizantes causa, no indivíduo, um impulso de entrada inicial no consumo dos anabolizantes, juntamente com uma motivação de incentivo e recompensa para o consumo dos mesmos (Brower, 2002). No segundo estágio, após o consumo indiscriminado de esteroides anabolizantes, a toxicodependência psicológica e fisiológica pode-se desenvolver, fazendo com que o usuário encontre uma dificuldade crescente de abandonar completamente o consumo dos esteroides anabolizantes. Nesta fase, o indivíduo apresenta sintomas que se enquadram nos critérios de diagnóstico para toxicodependência, deve receber tratamento para toxicodependência de esteroides anabolizantes, pois, na maior parte dos casos, utilizam outras drogas como: bromocriptina, usada em combinação com os esteroides anabolizantes para reduzir a gordura corporal, além do uso simultâneo de anfetaminas, opióides, cocaína, álcool (Gráfico 1).

Sabe-se que, nos últimos 30 anos, houve uma evolução nos resultados dos estudos em modelos animais e seres humanos, que documentaram fortes evidências clínicas para a toxicodependência (Gráfico 1) dos esteroides anabolizantes androgênicos (Arnedo et al., 1999; Kanayama et al., 2009b; Keane, 2003; Milhorn, 2018; Pope et al., 2000; Williamson E Young, 1992; Yates, 2000). Porém, o fato de ainda existirem incertezas relacionadas ao mecanismo de adição se deve as ambiguidades, tanto das características do conceito de toxicodependência destes fármacos, quanto à falta de uma melhor compreensão dos mecanismos de adição dos esteroides anabolizantes (Keane, 2003). Igualmente, Kanayama et al. (2009a) atribuem, à falta de esclarecimento total do mecanismo de adição dos esteroides anabolizantes, o fato de os problemáticos efeitos psicoativos destas substâncias permanecerem subestimados pelas instituições responsáveis pela elaboração do Manual Diagnóstico e Estatístico de Transtornos Mentais. Portanto, reforçamos a necessidade de se realizarem novas pesquisas, utilizando outros 
procedimentos metodológicos, com a finalidade de se preencher esta lacuna. É importante esclarecer o funcionamento do mecanismo de adição dos esteroides anabolizantes androgênicos e o fato destas substâncias afetarem uma variedade de neurotransmissores corticais, em destaque o sistema opioidérgico (Arnedo et al., 1999; Kashkin \& Kleber, 1989; Kanayama et al., 2009a; Wood, 2008), podendo levar ao desenvolvimento de uma maior sensibilidade para os narcóticos opióides e estimulantes centrais (Arnedo et al., 1999; Brower, 2002; Mhillaj et al., 2015). Assim, sugerimos futuras investigações para esclarecer como a interação entre outras substâncias psicoativas, combinadas ao uso de esteroides anabolizantes, altera o funcionamento do sistema de recompensa do cérebro humano, e para perceber se o consumo abusivo destes fármacos acarreta outras psicopatologias que ainda não foram relacionadas ao abuso destas substâncias.

\section{Dados de Experimentos em Modelos Animais}

As alterações no sistema de recompensa cerebral provocadas pelo consumo de esteroides anabolizantes androgênicos, inicialmente, foram documentadas na literatura científica através dos resultados de experimentos com modelos animais (Gráfico 2). Estas investigações contribuem para avaliar o impacto dos esteroides anabolizantes nos mecanismos psicobiológicos subjacentes ao comportamento. Estudos com animais são mais viáveis, por questões bioéticas e por apresentarem variáveis que podem ser mais facilmente controladas pelo pesquisador, permitindo uma mensuração direta de parâmetros comportamentais. Contudo, como discutido na sessão anterior, algumas destas pesquisas apresentam resultados contraditórios e que geram controvérsias.

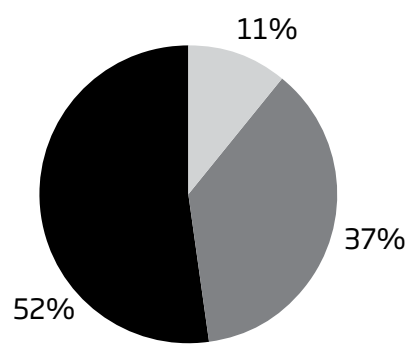

Pesquisas publicadas no Brasil em língua portuguesa

Estudos com modelos animais

Estudos com seres humanos

Gráfico 2. Estado atual das pesquisas revisadas sobre o impacto do uso indiscriminado de EAA no sistema de recompensa cerebral.

Os estudos experimentais com modelos animais revisados têm semelhanças, como a utilização do método de preferência condicionada de lugar (PCL) e autoadministração, onde os animais recebem sempre, no mesmo local, as doses de esteroides anabolizantes. Assim, os pesquisadores obtêm dados, inferindo as propriedades recompensatórias da substância utilizada, observando o tempo de permanência dos animais nestes lugares específicos, que são associados 
à administração do fármaco, e verificam que as doses deste hormônio se tornaram um estímulo de controle discriminativo nos modelos animais (Arnedo et al., 2000; Beun, Jansen, Slangen, \& Van de Poll, 1992; Pakard, Cornell, \& Alexander, 1997; Peters \& Wood, 2005; Sauerbier, 2014; Wood, Johnson, Chu, Schad, \& Self, 2004).

Os animais desenvolvem o aumento da autoadministração da substância, preferência condicionada de lugar, aumento da agressividade, pois os esteroides anabolizantes afetaram as vias dopaminérgicas, núcleo accumbens, área tegmentar ventral, sistema límbico e córtex frontal, que são muito importantes para o funcionamento do sistema de recompensa do cérebro. Por isto, o primeiro modelo de adição aos esteroides anabolizantes androgênicos, exposto na secção anterior, é considerado o modelo explicativo do vício com maior validade. Ficou claro que o mecanismo de adição dos esteroides anabolizantes, assim como no mecanismo de ação das demais drogas clássicas, altera os sistemas dopaminérgicos e serotonérgicos. O núcleo accumbens é ativado pela exposição aos esteroides anabolizantes, podendo causar toxicodependência (Clark et al., 1996; Johansson, Steensland, Nyberg, \& Chahl, 2002; Mhillaj et al., 2015; Packard et al., 1997; Sauerbier, 2014).

No entanto, Pedroso (2012), Mhillaj et al. (2015) e Ribeiro (2014) advertem que a quantidade de estudos que investigam os efeitos dos esteroides anabolizantes nos sistemas glutamatérgico e GABAérgico ainda são limitados. Com isto, reforçamos a necessidade de se realizar em novas pesquisas que esclareçam a capacidade de toxicodependência dos esteroides em vias não clássicas, assim como outras possíveis alterações ainda não verificadas nos estudos já realizados. Outras pesquisas com modelos animais avaliaram o impacto dos anabolizantes sob o número médio dos corpos dos neurônios do córtex cerebral, administrando esteroides anabolizantes nos animais e, posteriormente, estimulando-os fisicamente através da natação. Desta forma, os pesquisadores analisaram a quantificação dos neurônios, constatando, assim, a diminuição de $30 \%$ da densidade média dos corpos dos neurônios nos animais submetidos ao tratamento com esteroides anabolizantes androgênicos (Damião et al., 2012). Com isto, concluíram que o consumo indiscriminado de esteroides anabolizantes pode levar a degenerações severas no sistema nervoso central, produzindo perda de atividades cerebrais e cognitivas (Damião et al., 2012; Tabela 1).

Em outros estudos que buscaram perceber os prejuízos dos esteroides anabolizantes na estrutura neural, a testosterona ocasionou uma elevação significativa do glutamato, isso teve como consequência a diminuição dos corpos celulares de neurônios (Ribeiro, 2014; Yang et al., 2002), aumento significativo da ação excitotóxica do glutamato a uma concentração de $10 \mu M$, ocasionando acidente vascular cerebral em roedores (Yang et al., 2002). Causou a morte dos neurônios da amígdala medial e no núcleo póstero-ventral da amígdala dos camundongos, trazendo sérios danos ao sistema nervoso central. Estimulou respostas emocionais de ansiedade e agressividade, que são associadas a estas áreas cerebrais afetadas (Ribeiro, 2014; Tabela 1). Com a aplicação deste procedimento metodológico de administração destes hormônios e estimulação da musculatura corporal, após a aplicação das substâncias anabólicas, por um período de 30 dias, pode averiguar-se que os esteroides anabolizantes androgênicos não causam a diminuição dos corpos neurais no cerebelo dos ratos. Assim, os autores concluem que os esteroides anabolizantes não são atraídos pelos neurônios de Purkinje, pois o cerebelo não possui neurorreceptores para estas substâncias anabólicas (Silva, Esteves, Júnior, \& Nogueira, 2012), reforçando, assim, as evidências de que os esteroides anabolizantes aumentam as chances de ocorrência da neurodegeneração dos neurônios que compõem o córtex cerebral (Caraci et al., 2011; Cunningham, Giuffrida, \& Roberts, 2009; Orlando et al., 2007; Tabela 1). 
$\mathrm{Na}$ maioria dos estudos realizados em modelos animais, porém, os esteroides anabolizantes foram administrados em doses baixas por curtos períodos de tempo (Clark et al.,1996; Damião et al., 2012; Martínez-Sanchís, Slavador, Moya-Albiol, Gonzalez-Bono, E Simon, 1998; Ribeiro, 2014; Silva et al., 2012; Yang et al., 2002). Desta forma, os resultados encontrados distanciam-se significativamente do que ocorre no sistema de recompensa do cérebro de seres humanos, que, por um longo período temporal, realizam o consumo de altas doses destes fármacos.

Nos estudos analisados, observou-se que nem todos os modelos animais que foram submetidos a experimentos com esteroides anabolizantes androgênicos desenvolveram toxicodependência (Arnedo et al., 2000; Grönbladh et al., 2016; Negus et al., 2001). Este dado demonstra que a realização de novas pesquisas é necessária para detectar quais são os fatores de predisposição da toxicodependência de esteroides anabolizantes androgênicos. É uma lacuna a ser investigada nas pesquisas empíricas, tanto em modelos animais quanto em seres humanos.

\section{Dados da Investigação em Seres Humanos}

Boa parte das investigações realizadas com humanos resulta de estudos de caso realizados através de atendimentos de urgência médica e/ou psicológica (Akhter, Hyder, \& Ahmed, 1994; Alaraj, Chamoun, Dahdaleh, Haddad, \& Comair, 2005; Arnedo et al., 1999; Hays, Littleton, \& Stillner, 1990; Kanayama et al., 2009b; Ranjan etal., 2014; Shimada et al., 2012; Tennant et al., 1988). Desta forma, é possível evidenciar de forma descritiva a manifestação de toxicodependência, a síndrome de abstinência que acarretada o uso indiscriminado dos esteroides anabolizantes (Arnedo et al., 1999; Hays et al., 1990; Kanayama et al., 2009b; McBride et al., 1996; Ranjan et al., 2014). Os estudos de casos também contribuíram para a evolução destas pesquisas, através dos registros de evidencias da doença cerebrovascular em praticantes do consumo exacerbado de esteroides anabolizantes androgênicos. Visto que a doença cerebrovascular é uma consequência grave do consumo indiscriminado destes fármacos, pois pode ocasionar morte encefálica súbita, podendo acontecer de forma precoce (Akhter et al., 1994; Alaraj et al., 2005; Shimada et al., 2012; Tabela 1).

A partir das evidências empíricas supracitadas, nos últimos anos, pode-se perceber a evolução das pesquisas e métodos utilizados nas investigações sobre o impacto neural do consumo abusivo dos esteroides anabolizantes a longo prazo. Kaufman et al. (2015) realizaram, na Universidade de Harvard, um estudo clínico pioneiro, através da análise sistemática de neuroimageim de ressonância magnética estrutural, que avaliou os efeitos no cérebro humano do uso de esteroides anabolizantes androgênicos, a longo prazo, em usuários de meia idade. Os resultados indicaram que o uso de esteroides anabolizantes, a longo prazo, altera estruturas cerebrais como a amígdala, estrutura associada à motivação do uso e toxicodependência de opióides. Nos usuários houve uma redução do volume total da amígdala $(p<.001)$. A análise volumétrica FreeSurfer revelou os volumes bilaterais da amígdala maiores em usuários de esteroides anabolizantes do que nos indivíduos não usuários $(p=.056)$ e detectou-se um aumento do volume da amígdala direita $(p=.002)$. Os pesquisadores observaram, ainda, que em estado de descanso, houve uma significativa diminuição do volume da amígdala direita e numerosas regiões do cérebro em usuários de esteroides anabolizantes, em comparação aos não usuários (Kaufman et al., 2015). 
As regiões cerebrais afetadas nos indivíduos usuários de esteroides anabolizantes incluem o dACC esquerdo, a lateral direita do núcleo accumbens, o hipocampo posterior direito, bem como, o núcleo caudado bilateral e o putamen, ínsula anterior, tálamo dorsomedial, giroscópio frontal superior, médio e inferior, giro pós-central, precúrio, córtex estelar, área de transição parieto-occipital, hemisférios cerebelares. Os usuários de esteroides anabolizantes também apresentaram conectividade reduzida entre amígdala direita e várias estruturas medianas, córtex cíngulo prégenioso, vermis cerebelar, mesencéfalo e áreas do tronco encefálico, glutamato em níveis elevados ( $p=.028$ ) nos usuários de esteroides anabolizantes (Kaufman et al., 2015).

Os autores apontam ainda que, em contraste, o acoplamento da amígdala esquerda foi reduzido em algumas regiões encefálicas, incluindo ínses anterior e posterior direito, córtex piriforme direito, amígdala prolongada e perpendicular superior direito. Estas alterações neurais induzem anormalidades psicoquímicas ${ }^{4}$, comportamentos agressivos, comportamentos de risco, prejuízo da memória visuoespacial dos indivíduos que fazem o uso crônico destes fármacos (Kaufman et al., 2015) (Tabela 1). Os dados da pesquisa de Seitz et al. (2017), também com a utilização de métodos de análise de neuroimagens, corroboram com os achados supracitados. Foi constatado que o consumo de esteroides anabolizantes, por um longo período de tempo, altera a integridade e a organização da substância branca do cérebro, consequentemente afeta os processos psicoquímicos relacionados à amígdala, afetando a função do sistema de recompensa neural (Tabela 1). Acarreta prejuízos para a neuroplasticidade, pois torna o córtex cerebral mais fino em regiões generalizadas. Com isto os volumes neuroanatômicos ficam significativamente menores, incluindo o total da substância cinzenta (Bjørnebekk et al., 2017).

Outras investigações com seres humanos identificaram que os esteroides anabolizantes acarretam no cérebro dos usuários a concussão, que se caracteriza como um traumatismo crânioencefálico que leva a manifestação de perdas transitórias da consciência, risco de encefalopatia traumática crônica (ETC), condições neurodegenerativas associadas às funções cognitivas e psiquiátricas alteradas (Namjoshi et al., 2016). Ocorre também uma redução na conectividade funcional do cérebro que acontece de forma simultânea com as consequências emocionais, comportamentais e cognitivas do uso dos esteroides anabolizantes. Reduz a conectividade entre a amígdala e a rede de modo padrão (DMN), entre a rede de atenção dorsal (DAN) e o circuito neural frontal que engloba o giro frontal superior e inferior (SFG/IFG) e o córtex cingulado anterior (ACC) (Westlye et al., 2017). Após a interrupção do consumo, os usuários passam a apresentar níveis significativamente mais baixos de testosterona plasmática e frequências mais altas de sintomas sugestivos de hipogonadismo, podendo desenvolver hipogonadismo adquirido, severa diminuição do hormônio antimülleriano (AMH) e prejuízo do hormônio Inibina B (Rasmussen et al., 2016).

Uma das consequências da neurodegeneração provocada pelos esteroides anabolizantes consiste na distorção da imagem corporal e dismorfia corporal, caracterizada por uma autopercepção corporal ilusória, onde o indivíduo se percebe magro e fraco, diferente do que

\footnotetext{
${ }^{4}$ A utilização do termo psicoquímico deve-se à ação dos esteroides anabolizantes afetar a composição da química cerebral e causar anomalias no funcionamento neural (neuronal), que podem ter como consequência diversas perturbações (Tabela 1).
} 
realmente é. Observa-se uma preocupação acentuada com esta ideia, obsessão em adquirir grandeza e definição muscular com a finalidade de possuir um corpo utópico (Kanayama, Barry, Hudson, \& Pope, 2006; Olivardia, Pope, \& Hudson, 2000; Olivardia, 2001; Tavares, 2015).

Os autores supracitados usaram de métodos de investigação diferentes com diferentes propósitos e obtiveram dados semelhantes, mostrando que o desenvolvimento da dismorfia corporal está relacionado com o consumo de esteroides anabolizantes androgênicos. Por isso, recomenda-se a realização de investigações futuras com o uso de outros métodos e abordagens de pesquisa para esclarecer como estas alterações estruturais, cognitivas e funcionais, provocadas pelo uso abusivo destas drogas, influenciam o desenvolvimento da dismorfia corporal. Além disso, perceber se os indivíduos, que consomem anabolizantes de forma abusiva e desenvolvem dismorfia corporal, possuem prevalência de traços de personalidade comuns, detectar quais são os fatores de predisposição para o desenvolvimento desta psicopatologia (Tabela 1).

Olivardia (2001), Peters, Copeland, e Dillon (1999), Petersson, Bengtsson, VoltaireCarlsson, e Thiblin (2010) e Pope et al. (2000) propõem uma hipótese dos indivíduos usuários de esteroides anabolizantes possuírem motivações subjetivas (Atkinson et al., 2002; Hilgard, 1970), que vão além de meros motivos estéticos, que subjazem o consumo abusivo de esteroides anabolizantes androgênicos. Assim, incentivamos a realização de novos estudos para melhor esclarecer a referida hipótese, pois os resultados de tal investigação empírica podem contribuir para promover o progresso de estratégias de prevenção do consumo indiscriminado destes fármacos.

\section{Lacunas na Investigação Científica sobre o Consumo de Esteroides Anabolizantes Androgênicos}

Não foram encontradas pesquisas empíricas realizadas com modelos animais, nem com seres humanos, sobre as consequências no sistema de recompensa cerebral, sistema nervoso central, provocadas pela interação dos esteroides anabolizantes com outras substâncias não anabólicas utilizadas por halterofilistas amadores, como o Synthol.

Não foram encontrados estudos que realizaram uma reprodução fidedigna com modelos animais no uso de doses altas destes fármacos, tal como praticado por halterofilistas amadores, sendo uma lacuna observada nas investigações em modelos animais (Arnedo et al., 2000; Clark et al., 1996; Damião et al., 2012; Johansson et al., 2002; Kindlundh et al., 2001; Kindlundh, Lindblom, Bergström, \& Nyberg, 2003; Martínez-Sanchís et al., 1998; Peters \& Wood, 2005; Ribeiro, 2014; Rejeski, Brubaker, Herb, Kaplan, \& Koritnik, 1988; Sauerbier, 2014; Silva et al., 2012; Zotti et al., 2014). Com a finalidade de preencher esta lacuna, recomendamos que, em futuras pesquisas com modelos animais, se faça a replicação da administração de altas doses de esteroides anabolizantes androgênicos por um período de tempo superior ao adotado nos estudos anteriores. Assim, procurando aproximar-se do período de tempo e das doses consumidas destes fármacos por halterofilistas amadores, para documentar o impacto que o tempo prolongado de administração de altas doses de esteroides pode causar aos neurônios do sistema de recompensa cerebral, sistema nervoso central e no comportamento.

Acentuamos que a realização de novos estudos empíricos, em seres humanos, sobre os impactos do consumo indiscriminado de esteroides anabolizantes no sistema de recompensa cerebral e sistema nervoso central são fundamentais, porque ao contrário dos modelos animais, os seres humanos podem desenvolver logo no inicio do uso, um padrão de toxicodependência de 
esteroides anabolizantes androgênicos (Kanayama et al., 2009a). Pois, o consumo abusivo destes fármacos acarreta, no sistema de recompensa cerebral, desequilíbrio nos neurotransmissores envolvidos nos processos mentais de recompensa e motivação (Arnedo et al., 1999; Atkinson et al., 2002; Mhillaj et al., 2015), causando no cérebro do indivíduo diversas alterações que podem estimular o uso frequente e em maiores doses destes fármacos, podendo levar-lhe a desenvolver um quadro de toxicodependência (Tabela 1).

No percurso desta investigação, observou-se que a maioria dos estudos com seres humanos são investigações que ocorreram em um curto espaço de tempo (Bjørnebekk et al., 2017; Brower, 2002; Brower, Blow, Young, \& Hill, 1991; Rasmussen et al., 2016; Westlye et al., 2017). Com a identificação desta lacuna metodológica, propomos a realização de futuras pesquisas longitudinais. É útil o uso de métodos de análise de neuroimagens, tanto em pesquisas realizadas com abordagem qualitativa quanto quantitativa, e em investigações que mesclam ambas as abordagens que tenham como objeto de estudo os usuários de esteroides anabolizantes.

Sugere-se, também, que após um processo de reformulação, atendendo às exigências dos paradigmas bioéticos, se realize a replicação em seres humanos das pesquisas que já foram realizadas com modelos animais e que apresentaram resultados negativos (Arnedo et al., 2000; Negus et al., 2001), para analisar uma correlação entre os resultados e avaliar de forma macroscópica os novos resultados.

No percurso da análise da literatura científica realizada, ficou claro que não existem casos documentados onde o uso terapêutico de esteroides anabolizantes androgênicos tenha causado toxicodependência. Esta é uma evidência de que os casos de adição estão diretamente relacionados com o consumo de doses elevadas destes fármacos.

Não foram encontrados, na literatura científica, relatos de trabalhos realizados por psicólogos do desporto, no âmbito da prevenção do consumo e abuso de esteroides anabolizantes em clubes, ginásios e academias de halterofilismo amador. Percebeu-se que esta é uma lacuna a ser preenchida, portanto, sugerimos a realização desta prática que pode contribuir para prevenção dos malefícios ao bem-estar humano, discutidos no presente estudo. Recomendase, também, que esta prática seja concomitantemente acompanhada por um estudo, para documentar o impacto benéfico na qualidade de vida de halterofilistas amadores decorrente do trabalho de psicólogos do desporto em clubes, ginásios e academias.

\section{Conclusão}

O desenvolvimento deste estudo permitiu-nos compreender que o consumo de esteroides anabolizantes androgênicos pode causar alterações no sistema de recompensa cerebral, trazendo prejuízos à qualidade de vida humana. Além disso, também nos permitiu contribuir para a discussão do problema contemporâneo de saúde pública, que consiste no uso indiscriminado destes fármacos para fins estéticos, considerando que o cérebro e os neurônios tomam parte nesta questão. Acreditamos, ainda, ter contribuído para a identificação e a análise da investigação sobre o estado desta questão da psicobiologia, visto que o consumo excessivo destas substâncias causa alterações psicológicas, bioquímicas e fisiológicas, afetando, assim, o comportamento de seus usuários.

Foram definidos os conceitos de esteroides anabolizantes androgênicos, como hormônios sintéticos derivados da testosterona, hormônio sexual masculino, que são terapeuticamente prescritos com a finalidade de tratar patologias específicas. Não foram 
encontrados casos onde o consumo terapêutico destes fármacos provocou toxicodependência. Porém, os mesmos vêm sendo utilizados com finalidades estéticas, por causa de seus efeitos tanto anabólicos, visto que eles promovem a hipertrofia muscular, quanto androgênicos, pois promovem o aumento das características secundárias masculinas. A compreensão do que são os esteroides anabolizantes serviu-nos de base para analisarmos a ação destes fármacos no sistema de recompensa cerebral.

Foi possivel notar a estreita relação entre o consumo de drogas, a ação da dopamina e as alterações no sistema de recompensa do cérebro que compõem um processo neural de recompensa e prazer, que acaba por estimular o uso frequente e em maiores doses de substâncias psicoativas ao definirmos que este sistema neural é composto por um circuito de zonas cerebrais que estão interligadas.

Como resultados de nossa análise, foi possível perceber que os estudos analisados revelam que as variações dos níveis de andrógenos sintéticos afetam os níveis de dopamina nesta área do cérebro, promovendo a recompensa que se caracteriza como um estímulo de prazer, desejo e satisfação. As concentrações de testosterona no núcleo accumbens, que tem receptores de andrógenos, promovem a interação entre a testosterona e o sistema de recompensa neural, produzindo intensas sensações de prazer, ocasionando uma hiperestimulação. Desta forma, os seus usuários passam a buscar doses, cada vez maiores, destas substâncias, causando, também, uma diminuição prolongada da transmissão do neurotransmissor serotonina no sistema nervoso central.

Analisou-se, ainda, que o consumo excessivo de esteroides anabolizantes atua no sistema nervoso central, aumentando a excitabilidade neuronal, prejudicando a qualidade do sono, causando sindrome de apneia, por obstruírem as vias aéreas superiores, prejudicando o sistema neuro-hormonal, causando alterações psiquiátricas, como distúrbios de humor, quadros depressivos, medo e ansiedade e alterações no sistema monoaminérgico, que regula o comportamento, gerando agressividade. Ainda, alterações no comportamento sexual e distúrbios na autoimagem, que se manifestam na forma de dismorfia corporal.

O consumo excessivo de esteroides anabolizantes, origina, ainda, uma baixa hormonal que leva o usuário a desenvolver hipogonadismo, como também acarreta danos no sistema cardiovascular, no sistema reprodutor e distúrbios metabólicos. Os esteroides anabolizantes estimulam a ação do glutamato, aumentando as chances de perda neuronal em diversas regiões cerebrais, podendo promover a diminuição de atividades cerebrais e cognitivas e podendo precipitar um aneurisma cerebral precoce, que pode ocasionar a morte cerebrovascular súbita.

Assim, acreditamos que os objetivos desta investigação bibliográfica do estado atual desta questão científica foram alcançados, pois definimos o que são os esteroides anabolizantes androgênicos e o que é o sistema de recompensa cerebral. Com a realização desta análise do estado desta questão, pôde-se perceber que o uso de esteroides anabolizantes em excesso pode causar efeitos nocivos ao sistema de recompensa cerebral, posto que estas substâncias alteram o funcionamento deste sistema, que tem um papel fundamental no reforço da toxicodependência de substâncias psicoativas. Percebemos que os casos de adição dos esteroides anabolizantes têm semelhanças com a toxicodependência de outras substâncias psicoativas clássicas.

Com a análise dos estudos selecionados, entendemos que, para responder de um modo ainda mais satisfatório a questão desta pesquisa, o ideal seria partir-se da análise de estudos clínicos realizados com seres humanos, analisando neuroimagens deste sistema neural em 
pessoas que fazem o uso indiscriminado de esteroides anabolizantes androgênicos, realizando, desta forma, uma documentação das evidências. Sugerimos a realização de futuros estudos que esclareçam completamente a ação dos esteroides anabolizantes androgênicos sobre o sistema de recompensa do cérebro humano, pois ainda existem divergências sobre o modelo de adição dos esteroides anabolizantes. Nem todas as alterações que os esteroides anabolizantes podem provocar no sistema de recompensa cerebral e sistema nervoso central foram completamente investigadas. Por exemplo, as alterações funcionais e estruturais, a relação destas modificações com o desenvolvimento da dismorfia corporal, ainda não foram totalmente elucidadas. Isso resulta em que seja questionado, no meio científico, se, de fato, estas substâncias causam toxicodependência e outros malefícios para os humanos.

Constatamos, por fim, que, pelo fato da toxicodependência causada pelos esteroides anabolizantes ainda ser pouco estudada no Brasil, tornam-se escassas as estratégias de prevenção da adição aos esteroides anabolizantes, por meio de políticas públicas nacionais e de psicólogos do desporto, atuando no âmbito da prevenção do consumo e do abuso de esteroides anabolizantes em clubes, ginásios e academias de halterofilismo amador, contribuindo, desta forma, para a prevenção dos malefícios para os seres humanos discutidos nesta pesquisa.

Conclui-se que a realização de novos estudos, com o uso de outros aspectos metodológicos, que explorem de uma forma mais profunda e documentem as evidências científicas das alterações provocadas pelo consumo de esteroides anabolizantes androgênicos no sistema de recompensa cerebral, faz-se muito importante para que haja um maior esclarecimento desta questão tão pertinente.

Tabela 2

Mapeamento Bibliográfico 1988-2018

\begin{tabular}{|c|c|c|c|}
\hline Título do Trabalho & Autor (es/as) & Ano & Metodologia \\
\hline $\begin{array}{l}\text { Anabolic steroid dependence with opioid-type } \\
\text { features }\end{array}$ & Tennant, Black, \& Voy & 1988 & Estudo de caso \\
\hline $\begin{array}{l}\text { Anabolic steroids and aggressive behavior in } \\
\text { cynomolgus monkeys }\end{array}$ & Rejeski et al. & 1988 & Método experimental \\
\hline $\begin{array}{l}\text { Hooked on hormones? An anabolic steroid addiction } \\
\text { hypothesis }\end{array}$ & Kashkin \& Kleber & 1989 & Ensaio \\
\hline Anabolic steroid dependence & Hays, Littleton, \& Stillner & 1990 & Estudo de caso \\
\hline $\begin{array}{l}\text { Symptoms and correlates of anabolic-androgenic } \\
\text { steroid dependence }\end{array}$ & Brower et al. & 1991 & Método Servey \\
\hline $\begin{array}{l}\text { Psychiatric effects of androgenic and anabolic- } \\
\text { androgenic steroid abuse in men: a brief review of } \\
\text { the literature }\end{array}$ & Williamson \& Young & 1992 & Revisão de literatura \\
\hline $\begin{array}{l}\text { Testosterone as appetitive and discriminative } \\
\text { stimulus in rats: Sex-and dose-dependent effects }\end{array}$ & $\begin{array}{l}\text { Beun, Jansen, Slangen, \& Van } \\
\text { de Poll }\end{array}$ & 1992 & Método experimental \\
\hline $\begin{array}{l}\text { Cerebrovascular accident associated with anabolic } \\
\text { steroid use in a young man }\end{array}$ & Akhter, Hyder, \& Ahmed & 1994 & Estudo de caso \\
\hline $\begin{array}{l}\text { Rewarding affective properties of intra-nucleus } \\
\text { accumbens injections of testosterone }\end{array}$ & Packard, Cornell, \& Alexander & 1997 & Método experimental \\
\hline
\end{tabular}


Tabela 2 (continuação)

Mapeamento Bibliográfico 1988-2018

\begin{tabular}{|c|c|c|c|}
\hline Título do Trabalho & Autor (es/as) & Ano & Metodologia \\
\hline Anabolic-androgenic steroids and brain reward & Clark, Lindenfeld, \& Gibbons & 1996 & Método experimental \\
\hline Anabolic steroids and the mind & Corrigan & 1996 & Revisão de literatura \\
\hline $\begin{array}{l}\text { Three cases of nalbuphine hydrochloride } \\
\text { dependence associated with anabolic steroid use }\end{array}$ & $\begin{array}{l}\text { McBride, Williamson, } \\
\text { \& Petersen }\end{array}$ & 1996 & Estudo de caso \\
\hline $\begin{array}{l}\text { Effects of chronic treatment with testosterone } \\
\text { propionate on aggression and hormonal levels in } \\
\text { intact male mice }\end{array}$ & Martínez-Sanchís et al. & 1998 & Método Experimental \\
\hline $\begin{array}{l}\text { Dependencia de los Esteroides Anabolizantes- } \\
\text { Androgenizantes y Mecanismos Subyacentes }\end{array}$ & $\begin{array}{l}\text { Arnedo, Martínez-Sanchís, \& } \\
\text { Salvador }\end{array}$ & 1999 & Estudo de caso \\
\hline $\begin{array}{l}\text { Dependence-producing potential of anabolic- } \\
\text { androgenic steroids }\end{array}$ & Midgley, Heather, \& Davies & 1999 & Ensaio clínico \\
\hline $\begin{array}{l}\text { Anabolic-androgenic steroids: User characteristics, } \\
\text { motivations, and deterrents }\end{array}$ & Peters, Copeland, \& Dillon & 1999 & Ensaio clínico \\
\hline $\begin{array}{l}\text { Nalbuphine hydrochloride dependence in anabolic } \\
\text { steroid users }\end{array}$ & Wines, Gruber, Pope, \& Lukas & 1999 & Ensaio clínico \\
\hline $\begin{array}{l}\text { Rewarding properties of testosterone in intact male } \\
\text { mice: a pilot study }\end{array}$ & Arnedo et al. & 2000 & Método Experimental \\
\hline $\begin{array}{l}\text { Anabolic-androgenic steroids as a gateway to opioid } \\
\text { dependence }\end{array}$ & Arvary, \& Pope & 2000 & Ensaio clínico \\
\hline $\begin{array}{l}\text { Muscle dysmorphia in male weightlifters: a case- } \\
\text { control study }\end{array}$ & Olivardia, Pope, \& Hudson & 2000 & $\begin{array}{l}\text { Ensaio clínico } \\
\text { randomizado }\end{array}$ \\
\hline Testosterone in psychiatry: risks and benefits & Yates & 2000 & Revisão de literatura \\
\hline $\begin{array}{l}\text { Mirror, morror on the wall, who's the largest of them } \\
\text { all? The features and phenomenology of muscle } \\
\text { dysmorphia }\end{array}$ & Olivardia & 2001 & $\begin{array}{l}\text { Método } \\
\text { Fenomenológico }\end{array}$ \\
\hline $\begin{array}{l}\text { The anabolic-androgenic steroid nandrolone } \\
\text { decanoate affects the density of dopamine receptors } \\
\text { in the male rat brain }\end{array}$ & Kindlundh et al. & 2001 & Método Experimental \\
\hline
\end{tabular}

Lack of evidence for opioid tolerance or dependence Negus et al.

in rhesus monkeys following high-dose anabolicandrogenic steroid administration

2001 Método Experimental

The anabolic androgenic steroid, nandrolone decanoate, increases the density of Fos-like Johansson-Steensland, Nyberg, \& Chahl

2002 Método Experimental immunoreactive neurons in limbic regions of guineapig brain

\begin{tabular}{llll}
\hline Anabolic steroid abuse and dependence & Brower & 2002 & Ensaio clínico \\
\hline $\begin{array}{l}\text { Testosterone increases neurotoxicity of glutamate } \\
\text { in vitro and ischemia-reperfusion injury in an animal } \\
\text { model }\end{array}$ & Yang et al. & 2002 & Método Experimental \\
\hline Anabolic steroids and dependence & Keane & 2003 & Revisão de literatura \\
\hline
\end{tabular}


Tabela 2 (continuação)

Mapeamento Bibliográfico 1988-2018

\section{Título do Trabalho}

The anabolic-androgenic steroid nandrolone induces alterations in the density of serotonergic 5HT $1 \mathrm{~B}$ and $5 \mathrm{HT} 2$ receptors in the male rat brain

Testosterone reinforcement: intravenous and intracerebroventricular self-administration in male rats and hamsters
Spontaneous subdural haematoma in anabolic steroids dependent weight lifters: reports of two cases and review of literature

\section{Autor (es/as)}

Kindlundh et al.

Wood et al.

Alaraj et al.

2005 Estudo de caso

\section{Ano Metodologia}

2003 Método Experimental

2004 Método experimental

Androgen dependence in hamsters: overdose, tolerance, and potential opioidergic mechanisms

Body image and attitudes toward male roles in anabolic-androgenic steroid users

Peters \& Wood

2005 Método Experimental

Nanomolar concentrations of anabolic-androgenic steroids amplify excitotoxic neuronal death in mixed mouse cortical cultures

\begin{tabular}{|c|c|c|c|}
\hline $\begin{array}{l}\text { Anabolic-androgenic steroid dependence? Insights } \\
\text { from animals and humans }\end{array}$ & Wood & 2008 & Revisão de literatura \\
\hline $\begin{array}{l}\text { Issues for DSM-V: Clarifying the Diagnostic Criteria } \\
\text { for Anabolic-Androgenic Steroid Dependence }\end{array}$ & Kanayama et al. & 2009 & Revisão de literatura \\
\hline $\begin{array}{l}\text { Anabolic-androgenic steroid dependence: an } \\
\text { emerging disorder }\end{array}$ & Kanayama et al. & 2009 & Estudo de caso \\
\hline $\begin{array}{l}\text { Features of men with anabolic-androgenic steroid } \\
\text { dependence: a comparison with nondependent AAS } \\
\text { users and with AAS nonusers }\end{array}$ & Kanayama, Hudson, \& Pope & 2009 & Ensaio clínico \\
\hline $\begin{array}{l}\text { Androgens induce dopaminergic neurotoxicity via } \\
\text { caspase-3-dependent activation of protein kinase C- }\end{array}$ & Cunningham et al. & 2009 & Ensaio clínico \\
\hline Illicit anabolic-androgenic steroid use & Kanayama, Hudson, \& Pope & 2010 & Ensaio clínico \\
\hline $\begin{array}{l}\text { Substance abusers' motives for using anabolic } \\
\text { androgenic steroids }\end{array}$ & $\begin{array}{l}\text { Petersson, Bengtsson, } \\
\text { Voltaire-Carlsson, \& Thiblin }\end{array}$ & 2010 & Método Servey \\
\hline $\begin{array}{l}\text { Neurotoxic properties of the anabolic androgenic } \\
\text { steroids nandrolone and methandrostenolone in } \\
\text { primary neuronal cultures }\end{array}$ & Caraci et al. & 2011 & Ensaio clínico \\
\hline Esteroides anabolizantes e o sistema nervoso & Pedroso & 2012 & Revisão de literatura \\
\hline $\begin{array}{l}\text { Quantificação de corpos de neurônios em } \\
\text { camundongos submetidos ao uso de Esteroides } \\
\text { Anabolizantes }\end{array}$ & Damião et al. & 2012 & Método experimental \\
\hline $\begin{array}{l}\text { Quantidade de células de Purkinje no Cerebelo de } \\
\text { camundongos sob o uso de esteroides anabolizantes }\end{array}$ & Silva et al. & 2012 & Método experimental \\
\hline Abuso e dependência de anabolizantes & Lemos et al. & 2012 & Revisão bibliográfica \\
\hline $\begin{array}{l}\text { Cerebral infarction in a young man using high-dose } \\
\text { anabolic steroids }\end{array}$ & Shimada et al. & 2012 & Estudo de caso \\
\hline
\end{tabular}

Kanayama, Barry, Hudson, \& 2006 Ensaio clínico

Pope randomizado

Orlando et al

2007 Ensaio clínico 
Tabela 2 (continuação)

Mapeamento Bibliográfico 1988-2018

\section{Título do Trabalho \\ Análise estereológica de neurônios do corpo amigdaloide e avaliação comportamental de camundongos sob o uso de esteroides anabolizantes}

Exercício físico, sistema de recompensa e esteroides Sauerbier anabólicos androgênicos

\section{Autor (es/as)}

Ribeiro

Ano Metodologia

2014 Dissertação de mestrado e método experimental

2014 Dissertação de mestrado, ensaios pré-clínicos e revisão de literatura

Dependence on Anabolic-androgenic steroids: A case Ranjan et al. report and brief review

\begin{tabular}{llll}
\hline $\begin{array}{l}\text { Chronic nandrolone administration induces } \\
\text { dysfunction of the reward pathway in rats }\end{array}$ & Zotti et al. & 2014 & Método experimental \\
\hline $\begin{array}{l}\text { Effects of anabolic-androgens on brain reward } \\
\text { function }\end{array}$ & Mhillaj et al. & 2015 & Revisão de literatura \\
\hline $\begin{array}{l}\text { Brain and cognition abnormalities in long-term } \\
\text { anabolic-androgenic steroid users }\end{array}$ & Kaufman et al. & 2015 & Ensaio clínico \\
\hline
\end{tabular}

The neurobiology and addiction potential of anabolic Grönbladh, Nylander, \& Hallberg 2016 Revisão de literatura androgenic steroids and the effects of growth

hormone

\begin{tabular}{llcl}
\hline $\begin{array}{l}\text { Former abusers of anabolic androgenic steroids } \\
\text { exhibit decreased testosterone levels and } \\
\text { hypogonadal symptoms years after cessation: a case- } \\
\text { control study }\end{array}$ & Rasmussen et al. & & \\
\hline $\begin{array}{l}\text { Chronic exposure to androgenic-anabolic steroids } \\
\text { exacerbates axonal injury and microgliosis in the } \\
\text { CHIMERA mouse model of repetitive concussion }\end{array}$ & Namjoshi et al. & 2016 & Ensaio clínico \\
$\begin{array}{l}\text { Structural Brain Imaging of Long-Term Anabolic- } \\
\text { Androgenic Steroid Users and Nonusing Weightlifters }\end{array}$ & Bjørnebekk et al. & 2017 & Ensaio clínico \\
\hline $\begin{array}{l}\text { Brain connectivity aberrations in anabolic-androgenic } \\
\text { steroid users }\end{array}$ & Westlye et al. & 2017 & Entrevistas, estudo \\
\hline $\begin{array}{l}\text { White matter abnormalities in long-term anabolic- } \\
\text { androgenic steroid users: A pilot study }\end{array}$ & Seitz et al. & 2017 & Método Experimental \\
\hline \begin{tabular}{l} 
Anabolic Steroid Dependence \\
\hline
\end{tabular} & Milhorn & 2018 & Revisão de literatura \\
\hline
\end{tabular}




\section{Referências}

Abrahin, O. S. C., Moreira, J. K. R., Nascimento, V. C., \& Sousa, E. C. (2011). Análise sobre os estudos científicos do uso de esteroides anabolizantes no Brasil: Um estudo de revisão. FIEP Bulletin, 81, 331-335. Retirado de http://www.fiepbulletin.net/index.php/ fiepbulletin/article/view/353/653

Abrahin, O. S. C., \& Sousa, E. C. (2013). Esteroides anabolizantes androgênicos e seus efeitos colaterais: Uma revisão crítico-científica. Revista da Educação Física/UEM, 24, 669-679. doi:10.4025/reveducfis.v24.4.17580

Akhter, J., Hyder, S., \& Ahmed, M. (1994). Cerebrovascular accident associated with anabolic steroid use in a young man. Neurology, 44, 2405-2405. doi:10.1212/WNL.44.12.2405

Alaraj, A. M., Chamoun, R. B., Dahdaleh, N. S., Haddad, G. F., \& Comair, Y. G. (2005). Spontaneous subdural haematoma in anabolic steroids dependent weight lifters: Reports of two cases and review of literature. Acta Neurochirurgica, 147, 85-88. doi:10.1007/ s00701-004-0415-0

Araújo, R. B., Oliveira, M. D. S., Pedroso, R. S., Miguel, A. C., \& Castro, M. D. G. T. D. (2008). Craving e dependência química: Conceito, avaliação e tratamento. Jornal Brasileiro de Psiquiatria, 57, 57-63. http://dx.doi.org/10.1590/S0047-20852008000100011

Arnedo, M. T., Martínez-Sanchís, S., \& Salvador, A. (1999). Dependencia de los esteroides anabolizantes-androgenizantes y mecanismos subyacentes. Psicothema, 11, 531-544. Retirado de http://www.psicothema.com/pdf/306.pdf

Arnedo, M. T., Salvador, A., Martinez-Sanchis, S., \& Gonzalez-Bono, E. (2000). Rewarding properties of testosterone in intact male mice: A pilot study. Pharmacology Biochemistry and Behavior, 65, 327-332. doi:10.1016/S0091-3057(99)00189-6

Arvary, D., \& Pope, H. G. (2000). Anabolic-androgenic steroids as a gateway to opioid dependence. New England Journal of Medicine, 342, 1532-1532. doi:10.1056/ NEJM200005183422018

Atkinson, R. L., Atkinson, R. C., Smith, E. E., Bem, D. J., \& Nolen-Hoeksena, S. (2002). Introdução à Psicologia de Hilgard (13 ${ }^{\mathrm{a}}$ ed.). Porto Alegre, Brasil: Artmed.

Batista, I. R., Almeida, P. P., Fadel, G., \& Bressan, R. A. (2010). Neurociência do uso de substâncias psicoativas: O cérebro e o prazer. In A. Diehl, D. C. Cordeiro, \& R. Laranjeira, (Eds.), Tratamentos farmacológicos para dependência química: Da evidência científica à pratica clínica (pp. 55-74). Porto Alegre, Brasil: Artmed.

Bear, M. F., Connors, B. W., \& Paradiso, M. A. (2002). Neurociências: Desvendando o Sistema Nervoso. ( $2^{\mathrm{a}}$ ed.). Porto Alegre, Brasil: Artmed.

Beun, R., Jansen, E., Slangen, J. L., \& Van de Poll, N. E. (1992). Testosterone as appetitive and discriminative stimulus in rats: Sex-and dose-dependent effects. Physiology \& Behavior, 52, 629-634. doi:10.1016/0031-9384(92)90389-J

Bjørnebekk, A., Walhovd, K. B., Jørstad, M. L., Due-Tønnessen, P., Hullstein, I. R., \& Fjell, A. M. (2017). Structural brain imaging of long-term anabolic-androgenic steroid users and nonusing weightlifters. Biological Psychiatry, 82, 294-302. doi:10.1016/j. biopsych.2016.06.017 
Boff, S. R. (2010). Esteroides anabólicos e exercício: Ação e efeitos colaterais. Revista Brasileira de Ciências e Movimento, 18, 81-88. Retirado de https://portalrevistas.ucb.br/index.php/ RBCM/article/view/1316/1666

Brower, K. J. (2002). Anabolic steroid abuse and dependence. Current Psychiatry Reports, 4, 377-387. doi:10.1007/s11920-002-0086-6

Brower, K. J., Blow, F. C., Young, J. P., \& Hill, E. M. (1991). Symptoms and correlates of anabolic-androgenic steroid dependence. Addiction, 86, 759-768. doi:10.1111/j.1360-0443.1991.tb03101.x

Bueno, J. L. O. (2016). Miguel Covian, Claude Bernard e as raízes da psicobiologia no Brasil. Revista Argentina de Ciencias del Comportamiento, 8, 22-29. Retirado de https://revistas. unc.edu.ar/index.php/racc/article/view/10455/BUEHISpdf

Campos, L. F. L. (2008). Métodos e técnicas de pesquisa em Psicologia. ( $4^{\mathrm{a}}$ ed.). Campinas, Brasil: Alínea.

Caraci, F., Pistara, V., Corsaro, A., Tomasello, F., Giuffrida, M. L., Sortino, M. A., ... Copaini, A. (2011). Neurotoxic properties of the anabolic androgenic steroids nandrolone and methandrostenolone in primary neuronal cultures. Journal of Neuroscience Research, 89, 592-600. doi:10.1002/jnr.22578

Castro, M. I. P. (2004). Do prazer à dependência. Revista Toxicodependências, 10(3), 49-56. Retirado de http://www.sicad.pt/BK/RevistaToxicodependencias/Lists/SICAD_Artigos/ Attachments/158/2004_03_TXT4.pdf

Clark, A. S., Lindenfeld, R. C., \& Gibbons, C. H. (1996). Anabolic-androgenic steroids and brain reward. Pharmacology Biochemistry and Behavior, 53, 741-745. doi:10.1016/00913057(95)02082-9

Corrigan, B. (1996). Anabolic steroids and the mind. The Medical Journal of Australia, 165, 222-226. Retirado de https://www.ncbi.nlm.nih.gov/pubmed/8773655

Costa, A. S. V. (2015). Neurotransmissores e drogas: Implicações e alterações clínicas (Dissertação de mestrado, Porto, Universidade Fernando Pessoa). Retirado de http://hdl.handle.net/10284/4827

Cunningham, R. L., Giuffrida, A., \& Roberts, J. L. (2009). Androgens induce dopaminergic neurotoxicity via caspase-3-dependent activation of protein kinase

Cठ. Endocrinology, 150, 5539-5548. doi:10.1210/en.2009-0640

Damião, B., Souza G. G., Nogueira, D. A., Rossi-Junior, W. C., Fernandes, G. J. M., \& Esteves, A. (2012). Quantificação de corpos de neurônios em camundongos submetidos ao uso de esteroides anabolizantes. Revista Neurociências, 20, 68-72. Retirado de http://www. revistaneurociencias.com.br/edicoes/2012/RN2001/originais\%2020\%2001/668\%20 original.pdf

Dartora, W. J., Wartchow, K. M., \& Acelas, A. L. R. (2014). O uso abusivo de esteroides anabolizantes como um problema de saúde pública. Revista Cuidarte, 5, 689-693. Retirado de http://www.revistacuidarte.org/index.php/cuidarte/article/view/107/171

Dewsbury, D. A. (1991). Psychobiology. American Psychologist, 46, 198-205. doi:10.1037/0003066X.46.3.198

Ferreira, A. M. C. (2007). Gravidade de dependência e motivação para tratamento (Monografia de licenciatura, Instituto Superior da Maia). Retirado de http://www.psicologia.pt/artigos/ textos/TL0088.pdf 
Garcia, L. F. (2013). O Cérebro em alta performance. São Paulo, Brasil: Gente.

Graeff, F. G. (1995). Drogas psicotrópicas e seu modo de ação. (4ª Ed.). São Paulo, Brasil: EPU. Grönbladh, A., Nylander, E., \& Hallberg, M. (2016). The neurobiology and addiction potential of anabolic androgenic steroids and the effects of growth hormone. Brain Research Bulletin, 126, 127-137. doi:10.1016/j.brainresbull.2016.05.003

Hays, L. R., Littleton, S., \& Stillner, V. (1990). Anabolic steroid dependence. The American Journal of Psychiatry, 147, 122a-122. doi:10.1176/ajp.147.1.122a

Herculano-Houzel, S. (2005). O cérebro em transformação. Rio de Janeiro, Brasil: Objetiva.

Herculano-Houzel, S. (2012). Sexo, drogas e rock'n'roll...E chocolate: O cérebro e os prazeres da vida cotidiana ( $2^{\mathrm{a}}$ Ed.). Rio de Janeiro, Brasil: Vieira $\delta$ Lent.

Hilgard, E. R. (1970). Introdution to Psychology. Nova York, NY: Harcourt, Brace \& World. Johansson-Steensland, P., Nyberg, F., \& Chahl, L. (2002). The anabolic androgenic steroid, nandrolone decanoate, increases the density of Fos-like immunoreactive neurons in limbic regions of guinea-pig brain. European Journal of Neuroscience, 15, 539-544. doi:10.1046/j.0953-816x.2001.01877.x

Kanayama, G., Barry, S., Hudson, J. I., \& Pope, H. G. (2006). Body image and attitudes toward male roles in anabolic-androgenic steroid users. American Journal of Psychiatry, 163, 697-703. Retirado de https://ajp.psychiatryonline.org/doi/pdf/10.1176/ajp.2006.163.4.697

Kanayama, G., Brower, K. J., Wood, R. I., Hudson, J. I., \& Pope, H. G. (2009a). Issues for DSM-V: Clarifying the diagnostic criteria for anabolic-androgenic steroid dependence. The American Journal of Psychiatry. 166, 642-645. doi:10.1176/appi.ajp.2009.08111699

Kanayama, G., Brower, K. J., Wood, R. I., Hudson, J. I., \& Pope, H. G. (2009b), Anabolicandrogenic steroid dependence: An emerging disorder. Addiction, 104, 1966-1978. doi:10.1111/j.1360-0443.2009.02734.x

Kanayama, G., Hudson, J. I., \& Pope, H. G. (2009). Features of men with anabolic-androgenic steroid dependence: a comparison with nondependent AAS users and with AAS nonusers. Drug \& Alcohol Dependence, 102, 130-137. doi: 10.1016/j.drugalcdep.2009.02. 008

Kanayama, G., Hudson, J. I., \& Pope, H. G. (2010). Illicit anabolic-androgenic steroid use. Hormones and Behavior, 58, 111-121. doi:10.1016/j.yhbeh.2009.09.006

Kashkin, K. B., \& Kleber, H. D. (1989). Hooked on hormones? An anabolic steroid addiction hypothesis. JAMA, 262, 3166-3170. doi: 10.1001/jama.1989.03430220089036

Kaufman, M. J., Janes, A. C., Hudson, J. I., Brennan, B. P., Kanayama, G., Kerrigan, A. R., .. . Pope Jr., H. G. (2015). Brain and cognition abnormalities in long-term anabolic-androgenic steroid users. Drug and Alcohol Dependence, 152, 47-56. doi:10.1016/ j.drugalcdep.2015.04.023

Keane, H. (2003). Anabolic steroids and dependence. Contemporary Drug Problems, 30, 541-562. doi:10.1177/009145090303000302

Kindlundh, A. M. S., Lindblom, J., Bergström, L., \& Nyberg, F. (2003). The anabolic-androgenic steroid nandrolone induces alterations in the density of serotonergic 5HT $1 \mathrm{~B}$ and $5 \mathrm{HT} 2$ receptors in the male rat brain. Neuroscience, 119, 113-120. doi:10.1016/S03064522(03)00120-9 
Kindlundh, A. M. S., Lindblom, J., Bergström, L., Wikberg, J. E. S., \& Nyberg, F. (2001). The anabolic-androgenic steroid nandrolone decanoate affects the density of dopamine receptors in the male rat brain. European Journal of Neuroscience, 13, 291-296. doi:10.1046/j.0953-816X.2000.01402.x

Lemos, T., Peluso, M., Carvalho, T., Valério, F., Marques, A. C. P. R., Ribeiro, M., ... Andrada, N. C. (2012). Abuso e dependência de anabolizantes. Retirado de https://diretrizes.amb.org. br/_BibliotecaAntiga/abuso_e_dependencia_de_anabolizantes.pdf

Lent, R. (2004). Cem Bilhões de Neurônios: Conceitos fundamentais de neurociência. São Paulo, Brasil: Atheneu.

Linden, M., \& Manns, M. (1980). Psicofarmacologia para psicólogos. São Paulo, Brasil: E.P.U. Lopes, R. A. O. (2015). O papel da testosterona sobre o sistema cardiovascular em homens com hipogonadismo (Dissertação de Mestrado, Porto, Instituto de Ciências Biomédicas de Abel Salazar, Universidade do Porto). Retirado de https://sigarra.up.pt/ffup/pt/pub_geral. show_file?pi_gdoc_id=613743

Martínez-Sanchís, S., Salvador, A., Moya-Albiol, L., Gonzalez-Bono, E., \& Simon, V. M. (1998). Effects of chronic treatment with testosterone propionate on aggression and hormonal levels in intact male mice. Psychoneuroendocrinology, 23, 275-293. doi:10.1016/S03064530(98)00005-5

Martins, C. M., Carijó, F. H., Almeida, M. C., Silveira, M., Mirailh, M. X. N., Peixoto, M. M., ... Sholl-Franco, A. (2005). Efeitos psicológicos do abuso de anabolizantes. Ciências $\mathcal{E}$ Cognição, 5, 84-91. Retirado de http://www.cienciasecognicao.org/revista/index.php/ cec/article/view/522

McBride, A. J., Williamson, K., \& Petersen, T. (1996). Three cases of nalbuphine hydrochloride dependence associated with anabolic steroid use. British Journal of Sports Medicine, 30, 69-70. doi:10.1136/bjsm.30.1.69

McGaugh, J. L., Weinberger, N. M., \& Whalen, R. E. (1970). Psicobiologia: As bases biológicas do comportamento. São Paulo, Brasil: Polígono.

Mello, M. T., Boscolo, R. A., Esteves, A. M., \& Tufik, S. (2005). O exercício físico e os aspectos psicobiológicos. Revista Brasileira de Medicina do Esporte, 11, 203-207. doi:10.1590/ S1517-86922005000300010

Midgley, S. J., Heather, N., \& Davies, J. B. (1999). Dependence-producing potential of anabolicandrogenic steroids. Addiction Research, 7, 539-550. doi: 10.3109/16066359909004404

Milhorn, H. T. (2018). Anabolic Steroid Dependence. In H. T. Milhorn (Org.), Substance use disorder: A guide for the primary care provider. (pp. 179-185). Cham, Germany: Springer. doi: 10.1007/978-3-319-63040-3_13

Minayo, M. C. D. S. (2012). Análise qualitativa: Teoria, passos e fidedignidade. Ciência \& Saúde Coletiva, 17, 621-626. doi:10.1590/S1413-81232012000300007

Mhillaj, E., Morgese, M. G., Tucci, P., Bove, M., Schiavone, S., \& Trabace, L. (2015). Effects of anabolic-androgens on brain reward function. Frontiers in Neuroscience, 9, 1-13. doi:10.3389/fnins.2015.00295

Namjoshi, D. R., Cheng, W. H., Carr, M., Martens, K. M., Zareyan, S., Wilkinson, A., .. . Wellington, C. L. (2016). Chronic exposure to androgenic-anabolic steroids exacerbates axonal injury and microgliosis in the CHIMERA mouse model of repetitive concussion. PloS One, 11. doi:10.1371/journal.pone.0146540 
Negus, S. S., Pope, H. G., Kanayama, G., Wines, J. D. Jr., \& Fischer, B. D. (2001). Lack of evidence for opioid tolerance or dependence in rhesus monkeys following high-dose anabolicandrogenic steroid administration. Psychoneuroendocrinology, 26, 789-796.doi:10.1016/ S0306-4530(01)00028-2

Nobrega-Therrien, S. M., \& Therrien, J. (2004). Os trabalhos científicos e o estado da questão. Estudos em Avaliação Educacional, 15, 5-16. doi:10.18222/eae153020042148

Nobrega-Therrien, S. M., \& Therrien, J. (2010). O estado da questão: Aportes teóricosmetodológicos e relatos de sua produção em trabalhos científicos. In I. M. S. Farias, J. B. C. Nunes, \& S. M. Nobrega-Therrien (Eds.), Pesquisa cientifica para iniciantes: Caminhando no labirinto (pp. 33-51). Fortaleza, Brasil: EdUECE.

Olds, J. (1970). Centros de prazer no cérebro. In J. L. McGaugh, N. M. Weinberger, \& R. E. Whalen (Eds.), Psicobiologia: As bases biológicas do comportamento (pp. 198-203). São Paulo, Brasil: Polígono.

Olds, J., \& Milner, P. (1954). Positive reinforcement produced by electrical stimulation of septal area and other regions of rat brain. Journal of Comparative and Physiological Psychology, 47, 419-427. doi:10.1037/h0058775

Olivardia, R. (2001). Mirror, mirror on the wall, who's the largest of them all? The features and phenomenology of muscle dysmorhia. Harvard Review Psychiatry, 9, 254-259. Retirado de http://www.tandfonline.com/doi/abs/10.1080/hrp.9.5.254.259?journalCode=ihrp20

Olivardia, R., Pope, H. G., \& Hudson, J. I. (2000). Muscle dysmorphia in male weightlifters: A case-control study. American Journal of Psychiatry, 157, 1291-1296. Retirado de https:// ajp.psychiatryonline.org/doi/pdf/10.1176/appi.ajp.157.8.1291

Orlando, R., Caruso, A., Molinaro, G., Motolese, M., Matrisciano, F., Togna, G., .. . Bruno, V. (2007). Nanomolar concentrations of anabolic-androgenic steroids amplify excitotoxic neuronal death in mixed mouse cortical cultures. Brain Research, 1165, 21-29. doi:10.1016/j.brainres.2007.06.047

Packard, M. G., Cornell, A. H., \& Alexander, G. M. (1997). Rewarding affective properties of intra-nucleus accumbens injections of testosterone. Behavioral Neuroscience, 111, 219-224. doi:10.1037/0735-7044.111.1.219

Pedroso, J. L. (2012). Esteroides anabolizantes e o sistema nervoso. Revista Neurociência, 20, 181-182. Retirado de http://www.revistaneurociencias.com.br/edicoes/2012/RN2002/ editorial\%2020\%2002/editorial\%20ZeLuis\%2020\%2002.pdf

Pereira, I. A. T. S. (2009). A Vigorexia e os esteroides anabolizantes androgénios em levantadores de peso. (Dissertação de licenciatura, Porto, Faculdade de Deporto da Universidade do Porto). Retirado de http://hdl.handle.net/10216/22466

Peters, R., Copeland, J., \& Dillon, P. (1999). Anabolic-androgenic steroids: User characteristics, motivations, and deterrents. Psychology of Addictive Behaviors, 13, 232-242. Retirado de http://psycnet.apa.org/buy/1999-03841-008

Peters, K. D., \& Wood, R. I. (2005). Androgen dependence in hamsters: overdose, tolerance, and potential opioidergic mechanisms. Neuroscience, 130, 971-981. doi:10.1016/ j.neuroscience.2004.09.063

Petersson, A., Bengtsson, J., Voltaire-Carlsson, A., \& Thiblin, I. (2010). Substance abusers' motives for using anabolic androgenic steroids. Drug $\&$ Alcohol Dependence, 111 , 170-172. doi:10.1016/j.drugalcdep.2010.04.008 
Pope, H. G., Phillips, K. A., \& Olivardia, R. (2000). O Complexo de Adônis: A obsessão masculina pelo corpo. Rio de Janeiro, Brasil: Campus.

Ranjan, R., Parmar, A., Pattanayak, R. D., \& Dhawan, A. (2014). Dependence on anabolicandrogenic steroids: A case report and brief review. Delhi Psychiatry Journal. 17, 481-484. Retrieved from http://medind.nic.in/daa/t14/i2/daat14i2p481.pdf

Rasmussen, J. J., Selmer, C., Østergren, P. B., Pedersen, K. B., Schou, M., Gustafsson, F., .. . Kistorp, C. (2016). Former abusers of anabolic androgenic steroids exhibit decreased testosterone levels and hypogonadal symptoms years after cessation: a case-control study. PloS One, 11. doi:10.1371/journal.pone.0161208

Rejeski, W. J., Brubaker, P. H., Herb, R. A., Kaplan, J. R., \& Koritnik, D. (1988). Anabolic steroids and aggressive behavior in cynomolgus monkeys. Journal of behavioral medicine, 11, 95-105. doi: 10.1007/BF00846172

Ribeiro, M. S. (2014). Análise estereológica de neurônios do corpo amigdaloide e avaliação comportamental de camundongos sob o uso de esteroides anabolizantes (Dissertação de mestrado, Universidade Federal de Alfenas). Retirado de https://bdtd.unifal-mg.edu. br:8443/handle/tede/582

Rossa, A. A. (2012). O Sistema de recompensa do cérebro humano. Revista Textual, 16, 4-11. Retirado de http://www.sinprors.org.br/textual/out2012/pdfs/O_Sistema_de_ recompensa.pdf

Rossa, A. A., \& Rossa, C. R. P. (2011). O aprendizado da leitura sob a perspectiva enatista: Relações com a neurobiologia do sistema cerebral de recompensa. In A. Trevisan, J. J. M. Mosqueira, V. W. Pereira (Eds.), Alfabetização e Cognição. (pp. 37-50). Rio Grande do Sul, Brasil: EDIPUCRS.

Sagoe, D., Molde, H., Andreassen, C. S., Torsheim, T., \& Pallesen, S. (2014). The global epidemiology of anabolic-androgenic steroid use: a meta-analysis and meta-regression analysis. Annals of Epidemiology, 24, 383-398. doi:10.1016/j.annepidem.2014.01.009

Sauerbier, M. H. S. (2014). Exercício físico, sistema de recompensa e esteroides anabólicos androgênicos. (Dissertação de Mestrado, Santa Catarina. Retirado de https://repositorio. ufsc.br/handle/123456789/129442

Seitz, J., Lyall, A. E., Kanayama, G., Makris, N., Hudson, J. I., Kubicki, ... Kaufman, M. J. (2017). White matter abnormalities in long-term anabolic-androgenic steroid users: A pilot study. Psychiatry Research: Neuroimaging, 260, 1-5. doi:10.1016/j. pscychresns.2016.12.003

Shimada, Y., Yoritaka, A., Tanaka, Y., Miyamoto, N., Ueno, Y., Hattori, N., \& Takao, U. (2012). Cerebral infarction in a young man using high-dose anabolic steroids. Journal of Stroke E Cerebrovascular Diseases, 21, 906-909. doi:10.1016/j.jstrokecerebrovasdis.2011.07.013

Silva, M. T. A. (1981). Avanços recentes em psicobiologia. Psicologia: Ciência e Profissão, 1, 61-77. Retirado de http://pepsic.bvsalud.org/scielo.php?script=sci_arttextEpid=S1414$98931981000100003 \varepsilon l n g=p t \& t l n g=p t$.

Silva, P. R. P., Danielski, R., \& Czepielewski, M. A. (2002). Esteroides anabolizantes no esporte. Revista Brasileira de Medicina do Esporte, 8, 235-243. doi:10.1590/S151786922002000600005 
Silva, D. K., Esteves, A., Júnior, W. C. R., \& Nogueira, D. A. (2012). Quantidade de células de Purkinje no cerebelo de camundongos sob o uso de esteroides anabolizantes. Revista Neurociências, 20, 200-203. doi:10.4181/RNC.2012.20.690.4p

Standaert, D. G., \& Galanter, J. M. (2012). Farmacologia da neurotransmissão dopaminérgica. In D. E. Golan, A. H. Tashjian, E. J. Armstrong, \& A. W. Armstrong (Eds.), Princípios da farmacologia (pp. 166-185). (2 ${ }^{\mathrm{a}}$ Ed.). Rio de Janeiro, Brasil: Guanabara Koogan.

Tavares, C. P. (2015). Aspectos psicofísicos da imagem corporal e a sua relação com a dismorfia muscular e a dependência de exercício. (Tese de doutoramento, Universidade Estadual Paulista, São Paulo). Retirado de http://hdl.handle.net/11449/139402

Teixeira, J. M. (1998). Factores biológicos e toxicodependência: Revisão de estudos no âmbito da neurobiologia das drogas. Revista Toxicodependências, 3, 3-26. Retirado de http:// www.sicad.pt/BK/RevistaToxicodependencias/Lists/SICAD_Artigos/Attachments/346/ artigo1.pdf

Tennant, F., Black, D. L., \& Voy, R. O. (1988). Anabolic steroid dependence with opioid-type features. The New England Journal of Medicine, 319, 578-578. doi: 10.1056/ NEJM198809013190910

Thompson, R. F. (1999). James Olds 1922-1976: A biographical memoir. Retirado de http://www.nasonline.org/publications/biographical-memoirs/memoir-pdfs/olds-james.pdf

Venâncio, D. P., Nóbrega, A. C. L., Tufik, S., \& Mello, M. T. (2010). Avaliação descritiva sobre o uso de esteroides anabolizantes e seu efeito sobre as variáveis bioquímicas e neuroendócrinas em indivíduos que praticam exercício resistido. Revista Brasileira de Medicina do Esporte, 16, 191-195. doi:10.1590/S1517-86922010000300007

Vosgerau, D. S. A. R., \& Romanowski, J. P. (2014). Estudos de revisão: Implicações conceituais e metodológicas. Revista Diálogo Educacional, 14, 165-189. doi:10.7213/dialogo. educ.14.041.DS08

Westlye, L. T., Kaufmann, T., Alnæs, D., Hullstein, I. R., \& Bjørnebekk, A. (2017). Brain connectivity aberrations in anabolic-androgenic steroid users. Neuroimage: Clinical, 13, 62-69. doi:10.1016/j.nicl.2016.11.014

Williamson, D. J., \& Young, A. H. (1992). Psychiatric effects of androgenic and anabolicandrogenic steroid abuse in men: A brief review of the literature. Journal of Psychopharmacology, 6, 20-26. doi:10.1177/026988119200600107

Wines, J. D., Gruber, A. J., Pope, H. G., \& Lukas, S. E. (1999). Nalbuphine hydrochloride dependence in anabolic steroid users. The American Journal on Addictions, 8, 161-164. doi:10.1080/105504999305965

Wood, R. I. (2008). Anabolic-androgenic steroid dependence? Insights from animals and humans. Frontiers in Neuroendocrinology, 29, 490-506. doi:10.1016/j.yfrne.2007.12.002

Wood, R. I., Johnson, L. R., Chu, L., Schad, C., \& Self, D. W. (2004). Testosterone reinforcement: intravenous and intracerebroventricular self-administration in male rats and hamsters. Psychopharmacology, 171, 298-305. doi:10.1007/s00213-003-1587-7

Yang, S. H., Perez, E., Cutright, J., Liu, R., He, Z., Day, A. L., \& Simpkins, J. W. (2002). Testosterone increases neurotoxicity of glutamate in vitro and ischemia-reperfusion injury in an animal model. Journal of Applied Physiology, 92, 195-201. doi: 10.1152/ jappl.2002.92.1.195 
Yates, W. R. (2000). Testosterone in psychiatry: risks and benefits. Archives of General Psychiatry, 57, 155-156.doi:10.1001/archpsyc.57.2.155

Zotti, M., Tucci, P., Colaianna, M., Morgese, M. G., Mhillaj, E., Schiavone, S., ... \& Trabace, L. (2014). Chronic nandrolone administration induces dysfunction of the reward pathway in rats. Steroids, 79, 7-13. doi:10.1016/j.steroids.2013.10.005 